\title{
IMPLEMENTASI SUPPLY CHAIN MANAGEMENT PADA TOKO ALAT-ALAT OLAH RAGA BERBASIS WEB. STUDI KASUS PADA DODI SPORT
}

\author{
Aep Suryaman ${ }^{1}$, Agus Wahyudin ${ }^{2}$, Dadan Nugraha ${ }^{3}$ \\ Fakultas Ilmu Komputer Universitas Kuningan
}

\author{
J1. Cut Nyak Dien No.36 A, Kel. Cijoho Kuningan 45513 \\ Email : aepS@gmail.com ${ }^{1}$, aguswahyudin@uniku.ac.id ${ }^{2}$, dadannugraha@uniku.ac.id ${ }^{3}$
}

\begin{abstract}
ABSTRAK - Supply Chain Management (SCM) adalah seperangkat metode yang diterapkan dan terintegrasi untuk pemasok, perusahaan, gudang dan area penyimpanan lainnya secara efektif dan efisien. Penelitian ini bertujuan untuk mempermudah manajemen persediaan barang, mulai dari proses pemesanan barang baik dari pemasok, pengadaan barang hingga pengelolaan barang kepada pelanggan. Dodi Sport adalah perusahaan di bidang peralatan olahraga yang menjual produk-produk seperti, celana, baju kaos, sepatu, tas, bola dan peralatan olahraga lainnya. Perusahaan ini berlokasi di Jalan Ciamis nomor 97 Windujanten Kadugede - Kuningan. Sistem yang dibuat menggunakan metode Rational Unified Process (RUP), desain sistem berbasis web dan menggunakan aplikasi pendukung seperti XAMPP, bahasa pemrograman desain menggunakan bahasa Hypertext Preprocessor (PHP) dan antarmuka pengguna desain dan DBMS (Database Management System) menggunakan MySQL , aplikasi ini membantu perusahaan untuk menyimpan data manajemen barang, pemesanan, pembelian, penjualan, pengembalian barang dan lainnya yang masih menggunakan sistem manual, atau belum terkomputerisasi dengan tujuan memaksimalkan kinerja dan juga keuntungan bagi perusahaan, pemasok, termasuk ujung pelanggan. Diharapkan dapat memberikan kepuasan kepada pemasok dan perusahaan sehingga menjalankan proses bisnis akan mudah.
\end{abstract}

Kata kunci: Web, RUP, SCM, Dodi Sport Kuningan.

ABSTRACT - Supply Chain Management (SCM) is a set of methods which is applied and integrated for suppliers, employers, warehouses and other storage areas effectively and efficiently. This study aims to facilitate the management of goods stock, starting from the process of ordering good from suppliers, supplying goods until managing the goods to the customers. Dodi Sport is a company in the field of sports equipment that sells products such as, pants, jersey shirts, shoes, bags, ball and other sport equipments. The company is located in at Ciamis Street number 97 Windujanten Kadugede Kuningan. The system created uses Rational Unified Process (RUP) method, web-base system design and using supporting applications such as XAMPP, the design programming language using Hypertext Preprocessor (PHP) language and the design user interface and DBMS (Database Management System) uses MySQL, this application helps companies to store data management of goods, ordering, purchasing, sales, returning goods and others that still uses manual system, or not computerized yet with the aim of maximizing the performance and also profits for the company, suppliers, including end customers. It is expected to provide satisfaction to suppliers and companies so that running the business process will be easy.

Keywords : Web, RUP, SCM, Dodi Sport Kuningan. 


\section{PENDAHULUAN}

\subsection{Latar Belakang Masalah}

Perkembangan teknologi dan informasi yang sangat pesat tentu saja sangat menggembirakan, mengingat segala sesuatu yang dilakukan manusia akan semakin mudah dengan adanya perkembangan teknologi informasi. Salah satu perkembangan teknologi informasi yang sampai saat ini banyak diminati adalah teknologi komputer. Kemudahan teknologi komputer dengan semua kelengkapan telah dapat memberikan segala informasi dengan kecepatan dan tingkat akurasi yang tinggi, sehingga pemanfaatannya semakin meluas tidak hanya di bidang teknologi informasi saja, tetapi di bidang ekonomi, hiburan, keamanan, bisnis, juga termasuk penggunaan dibidang pendidikan dan pemanfaatan bidang lainnya.

Dewasa ini dunia bisnis mengalami persaingan yang semakin ketat. Diimbangi dengan perkembangan alatalat teknologi dan juga teknologi informasi yang semakin canggih sehingga mempermudah suatu perusahaan untuk dapat meningkatkan kinerja usahanya dalam mencapai tujuan untuk mendapatkan laba semaksimal mungkin dengan pengorbanan atau modal yang minimal. dalam pencapaian tujuannya tidaklah mudah, setiap perusahaan dalam persaingannya pasti memiliki strategistrategi tersendiri untuk dapat memenangkan persaingan bisnisnya tersebut.

Dodi Sport merupakan perusahaan yang bergerak dalam bidang pembelian \& penjualan alat-alat olahraga. Dalam transaksi pembelian, penjualan barang yang ada masih menggunakan pembukuan sederhana, sehingga kurang efektif dan efisiennya waktu yang digunakan serta terkadang terjadi kesalahan data-data yang diakibatkan oleh rusak atau hilang yang disebabkan oleh karyawan, Belum adanya sistem informasi untuk mengelola manajemen barang, Tidak hanya itu dalam pengelolaan stok produk sering terjadinya kelebihan stok (upperstock) dan kekurangan stok (lowerstock) dikarenakan kurang adanya pengelolaan barang dengan baik.

Sistem Informasi Manajemen Persediaan merupakan sistem informasi yang mengelola data transaksi dan persediaan dalam gudang. Dalam sistem persediaan barang biasanya terdiri dari sistem penerimaan barang, sistem pembelian barang, dan sistem gudang.

Supply Chain Management serangkaian pendekatan yang digunakan untuk mengintegrasikan supplier secara efisien, sehingga barang-barang dapat didistribusikan dengan jumlah, lokasi dan waktu yang tepat, dengan maksud meminimalkan keseluruhan sistem. Jadi Supply Chain Management tidak hanya berorientasi pada urusan internal sebuah perusahaan melainkan juga urusan eksternal yang menyangkut hubugan dengan perusahaan-perusahaan partner.

Berdasarkan latar belakang diatas penulis membuat penelitian yaitu "Implementasi Supply Chain Management Pada Toko Alat-alat Olah Raga Berbasis Web. Studi Kasus Pada Dodi Sport”.

\subsection{Identifikasi Masalah}

Berdasarkan latar belakang masalah di atas, maka dapat di identifikasikan permasalahan yang ada yaitu :

1. Proses pencatatan pengelolaan stok barang masih manual sehingga resiko kehilangan data sering terjadi. 
2. Managerial harus mengontrol kelebihan atau kekurangan barang, terkadang perusahaan mengalami kekurangan stok ataupun jumlah stok yang berlebihan akibat manajemen rantai persediaan (supply chain) yang kurang baik.

3. Proses pelaporan barang sering mengalami keterlambatan dikarenakan input data dilakukan masih manual.

4. Belum adanya sistem komputerisasi untuk pengelolaan pembelian atau penjualan barang di Toko Dodi Sport.

\section{METODE PENELITIAN}

\subsection{Supply Chain Management (SCM)}

Supply Chain adalah suatu sistem tempat organisasi menyalurkan barang produksi dan jasanya kepada para pelanggannya. (Indrajit dan Djokoprantoto 2003).

Supply chain is a network of cinnected and interdependent organizations mutually and cooperatively working together to control, manage and improve the flow of material and information from suppliers to end users. (Indrajit dan Djokopranoto, 2003).

Persediaan rantai adalah suatu jaringan dari organisasi yang saling tergantung dan dihubungkan satu sama lain dan co-operatively bekerja sama untuk mengendalikan, mengatur dan meningkatkan aliran material dan informasi dari para penyalur ke pemakai akhir.

\subsection{UML (Unified Modelling \\ Language)}

UML (Unified Modelling Language) adalah salah satu alat bantu yang sangat handal di dunia pengembangan sistem yang berorientasi objek. Hal ini disebabkan UML
p-ISSN : 1858-3911, e-ISSN : 2614-5405

https://journal.uniku.ac.id/index.php/ilkom menyediakan bahasa pemodelan visual yang memungkinkan bagi pengembang sistem untuk membuat cetak biru atas visi mereka dalam bentuk yang baku, mudah dimengerti serta dilengkapi dengan mekanisme yang efektif untuk berbagi (sharing) dan mengkomunikasikan rancangan mereka dengan yang lain.

UML merupakan kesatuan dari bahasa pemodelan yang dikembangkan oleh Booch, Object Modeling Technique (OMT) dan Object Oriented Software Engineering (OOSE). Metode Booch dari Grady Booch sangat terkenal dengan nama metode Design Object Oriented. Metode ini menjadikan proses analisis dan design ke dalam empat tahapan iterative, yaitu: identifikasi kelas-kelas dan obyek obyek, identifikasi semantic dari hubungan obyek dan kelas tersebut, perincian interface dan implementasi. Keunggulan metode Booch adalah pada detil dan kayanya dengan notasi dan elemen.

Pemodelan OMT yang dikembangkan oleh Rumbaugh didasarkan pada analisis terstruktur pemodelan entity-relationship. Tahapan utama dalam metodologi ini adalah analisis, design sistem, design obyek dan implementasi. Keunggulan metode ini adalah dalam penotasian yang mendukung semua konsep Object Oriented. Metode OOSE dari Jacobson lebih member penekanan pada use case. OOSE memiliki tiga tahapan yaitu membuat model requirement dan analysis, design dan implementasi, dan model pengujian (test model). Keunggulan metode ini adalah mudah dipelajari karena memiliki notasi yang sederhana namun mencakup seluruh tahapan dalam rekayasa perangkat lunak.

Design UML, metode Booch, OMT dan OOSE digabungkan 
dengan membuang elemen-elemen yang tidak praktis ditambah dengan elemenelemen dari metode lain yang lebih efektif dan elemen-elemen baru yang belum ada pada metode terdahulu sehingga UML lebih ekspresif dan seragam dari pada metode lainnya..

\section{HASIL DAN PEMBAHASAN}

\subsection{Analisis yang Sedang Berjalan}

Analisis kegiatan operasional perusahaan yang sedang berjalan ini di deskripsikan dengan menggunakan rich picture diagram. Dimana rich picture diagram merupakan gambaran yang menerangkan bagaimana alur data berpindah dari satu bagian ke bagian lain yang akan dijelaskan pada gambar berikut ini:

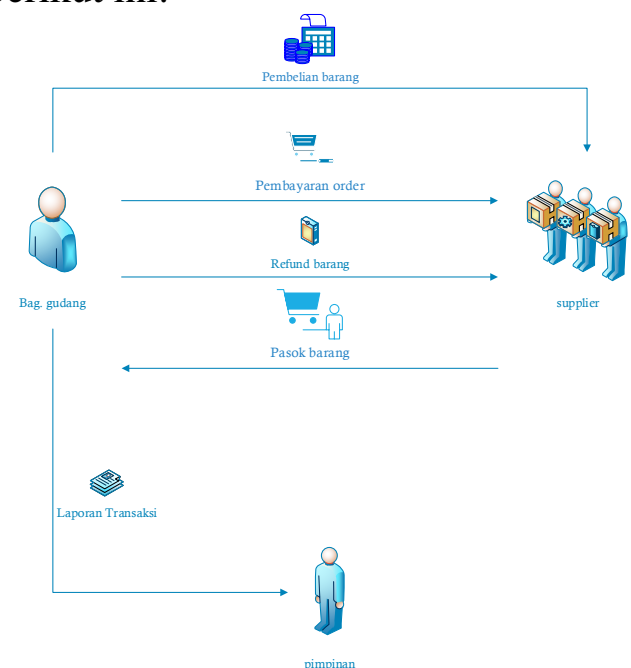

Gambar 1. Sistem yang sedang berjalan

\subsection{Sistem yang Diusulkan}

Analaisis sistem yang diusulkan dalam sistem pengelolaan barang di Toko Dodi Sport dapat dilihat dalam gambar berikut :

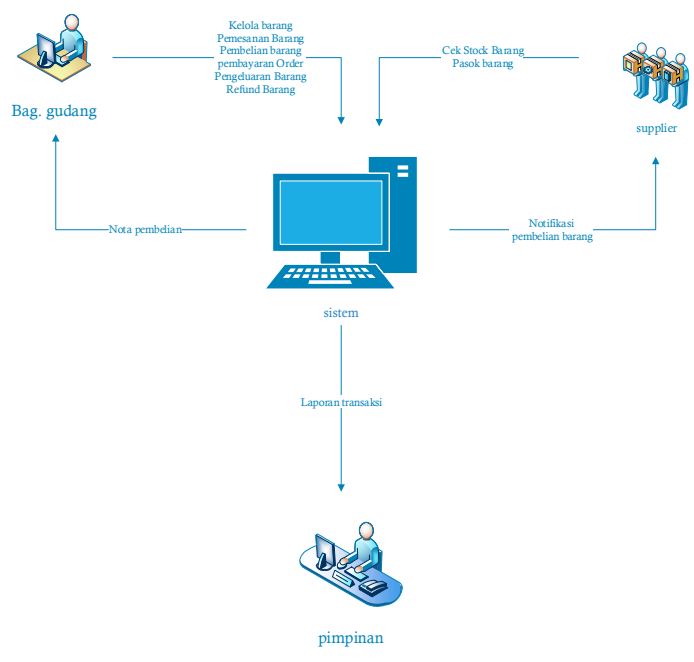

Gambar 2. Sistem yang diusulkan

\subsection{Perancangan Sistem}

\section{Use Case Diagram}

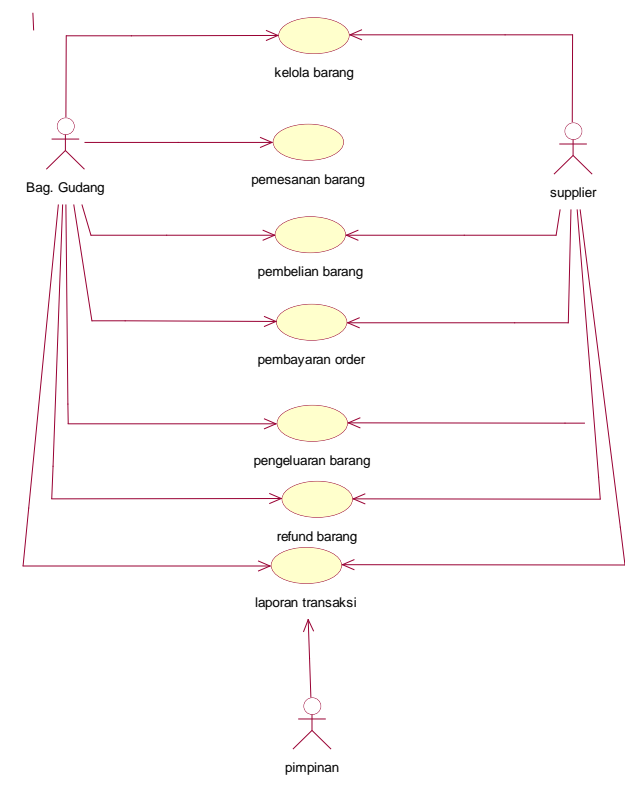

Gambar 3. Use Case Diagram

2. Activity Diagram

1) Activity Diagram Kelola Barang 
JURNAL NUANSA INFORMATIKA

Volume 12 Nomor 1, Januari 2018

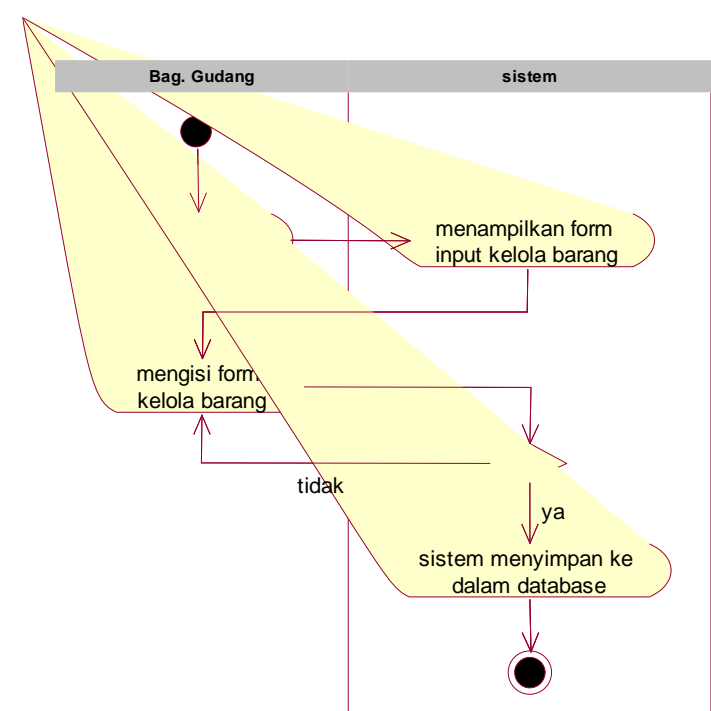

Gambar 4. Activity Diagram Kelola Barang

\section{Class Diagram}

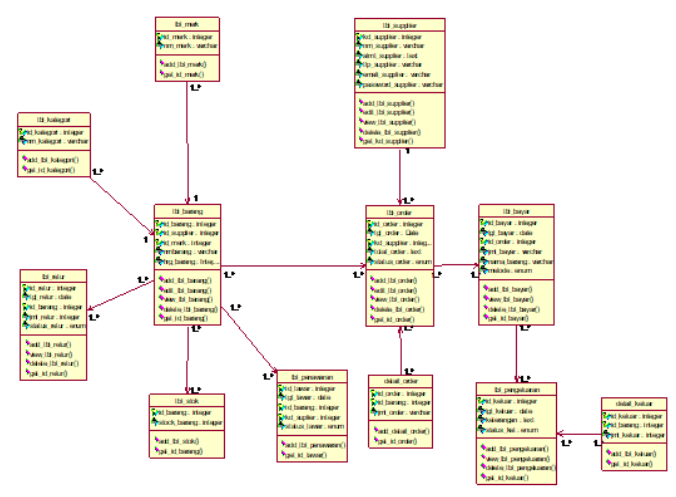

Gambar 5. Class Diagram

4. Sequence Diagram

1) Sequence Diagram Kelola

Barang

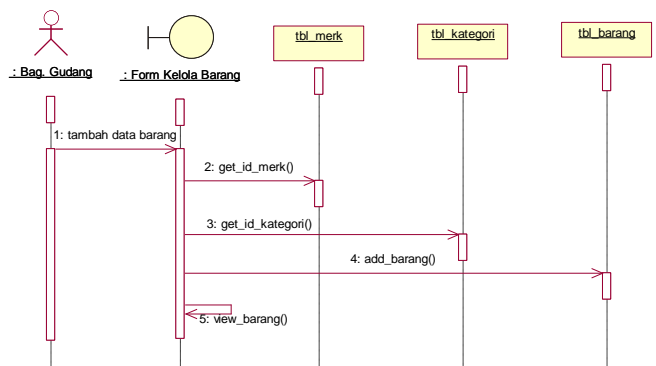

Gambar 6. Sequence Diagram Kelola Barang

\section{1) Halaman Login User}

p-ISSN : 1858-3911, e-ISSN : 2614-5405

https://journal.uniku.ac.id/index.php/ilkom

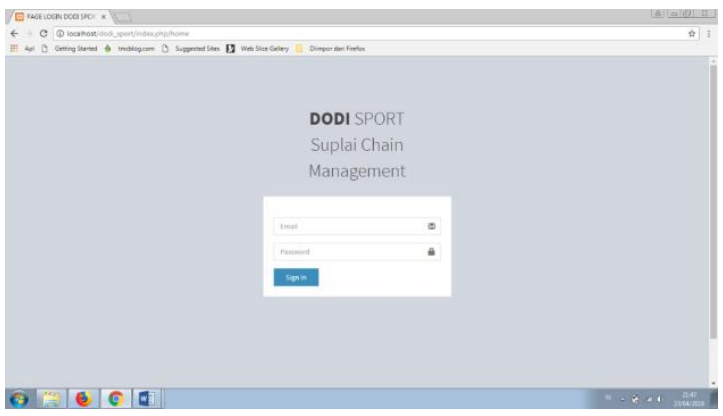

Gambar 7. Halaman login user

2) Halaman Home

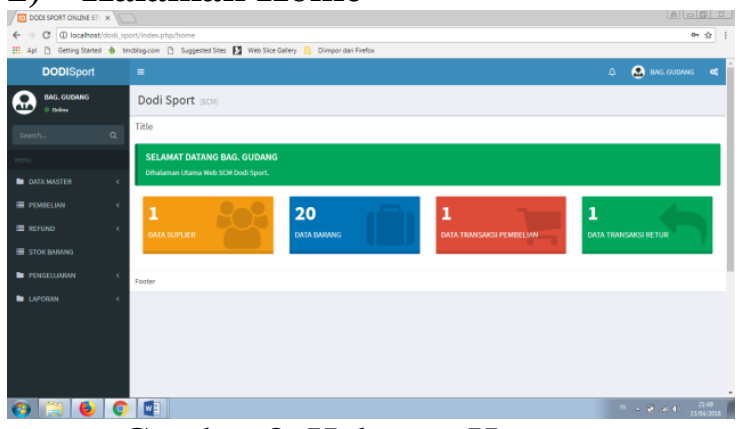

Gambar 8. Halaman Home

\section{3) Halaman Menu Data Barang}

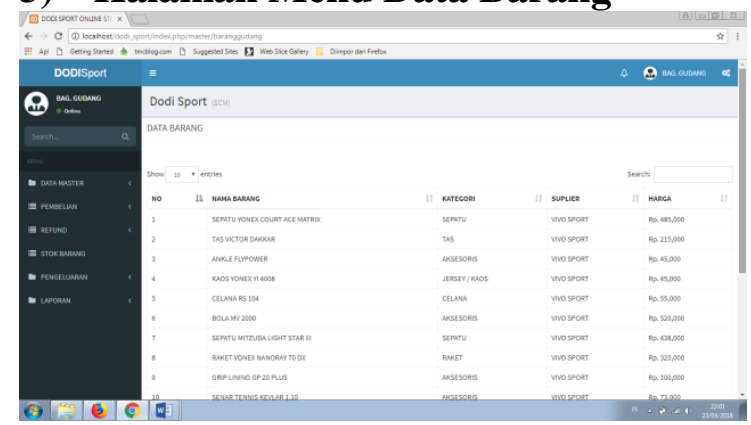

Gambar 9. Halaman Data pengelolaan barang

\section{4) Halaman Menu Kelola Supplier}

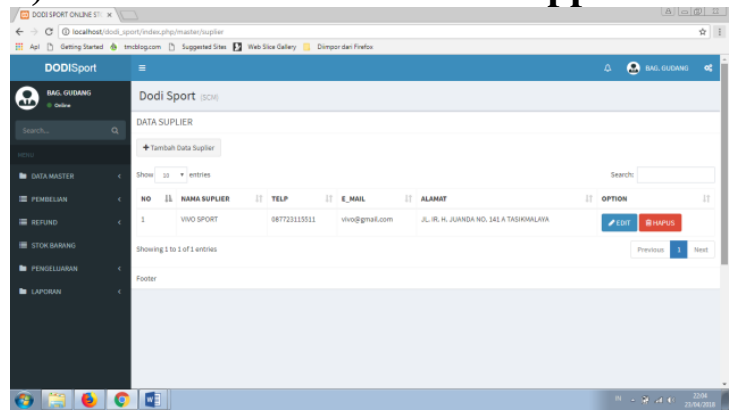

Gambar 10. Halaman Kelola Supplier 


\section{5) Halaman Kelola User}

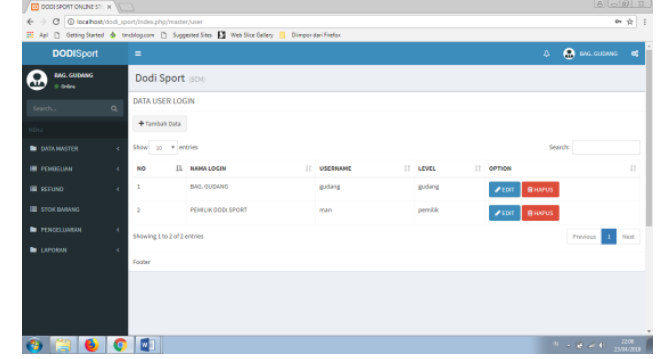

Gambar 11. Halaman Data kelola User

\section{6) Halaman Menu Kelola Kategori}

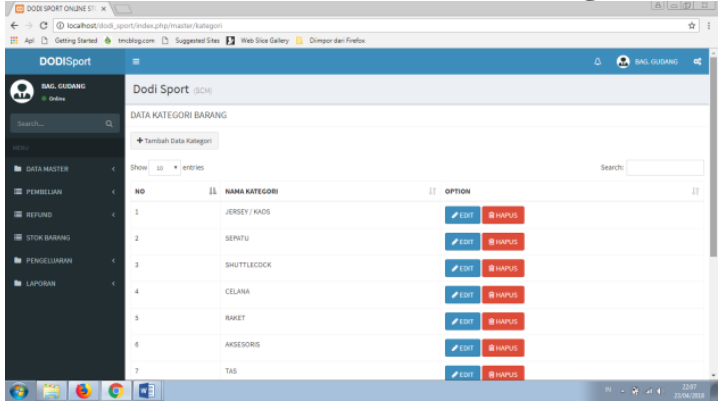

Gambar 12. Menu Kelola Kategori

\section{7) Form Pembelian Barang}

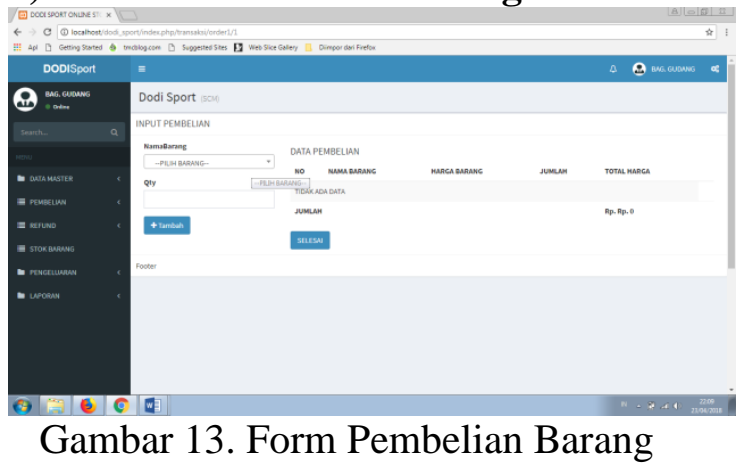

8) Menu Data Pembelian

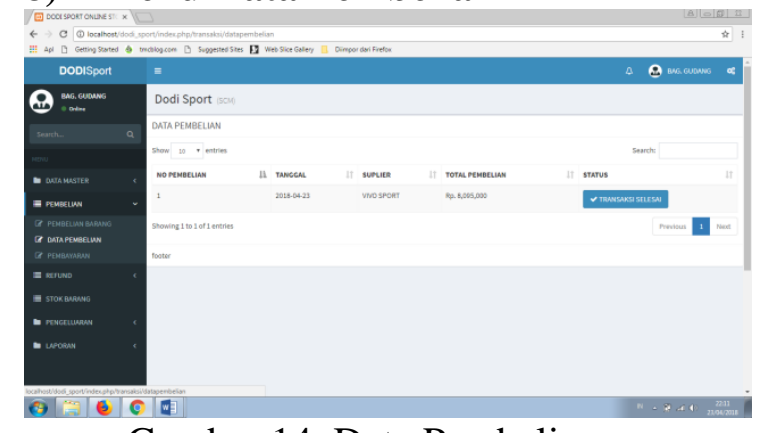

Gambar 14. Data Pembelian
p-ISSN : 1858-3911, e-ISSN : 2614-5405

https://journal.uniku.ac.id/index.php/ilkom

\section{9) Halaman Pembayaran}

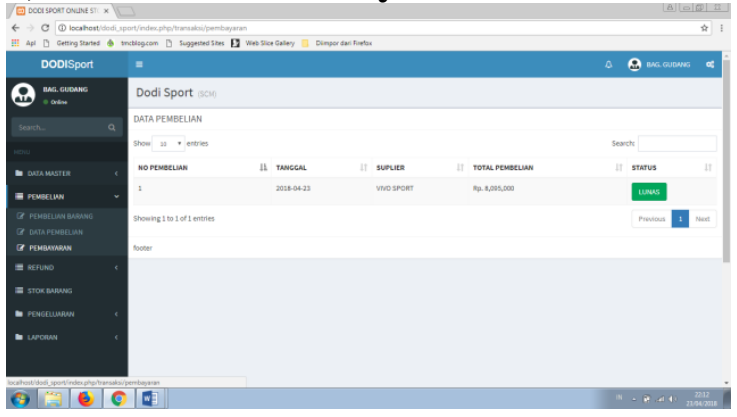

Gambar 15. Form pembayaran

\section{0) Form Menu Refund Barang}

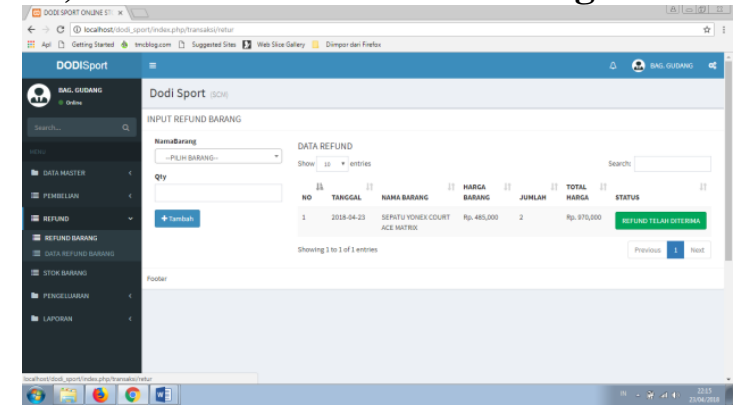

Gambar 16. Form Menu Refund Barang

\section{1) Halaman Data Refund Barang}

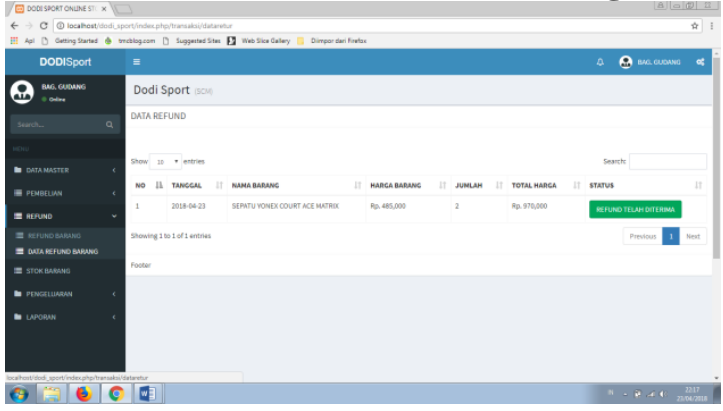

Gambar 17. Halaman Data Refund

Barang

\section{2) Halaman Stock Barang}

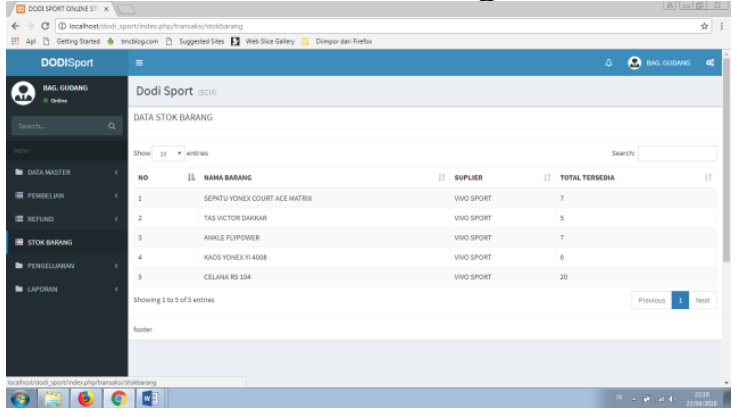

Gambar 18. Halaman Stock Barang 


\section{3) Laporan Pembelian}

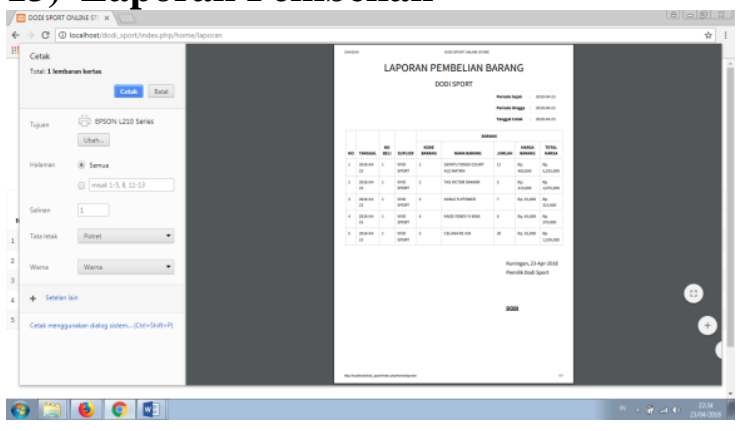

Gambar 19. Laporan Pembelian

14) Laporan Stock Barang

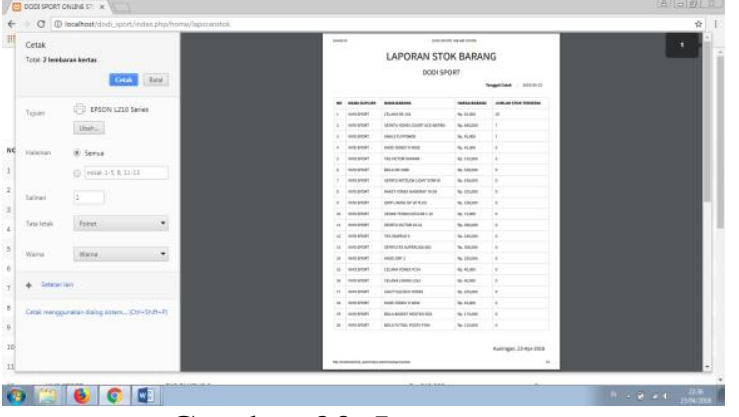

Gambar 20. Laporan

15) Laporan Refund Barang

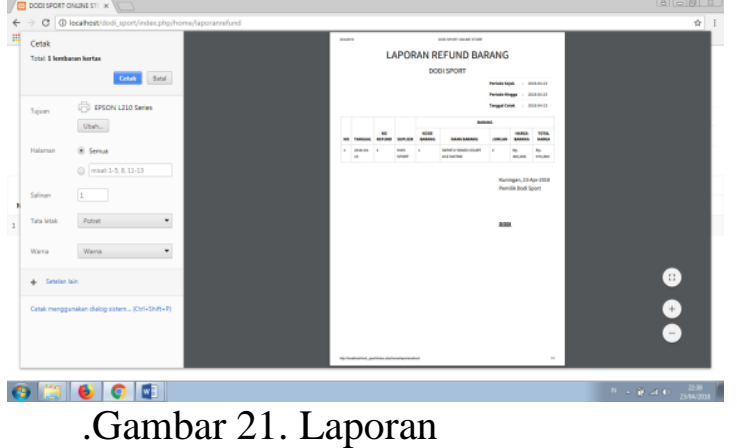

16) Lampiran Nota Pembelian

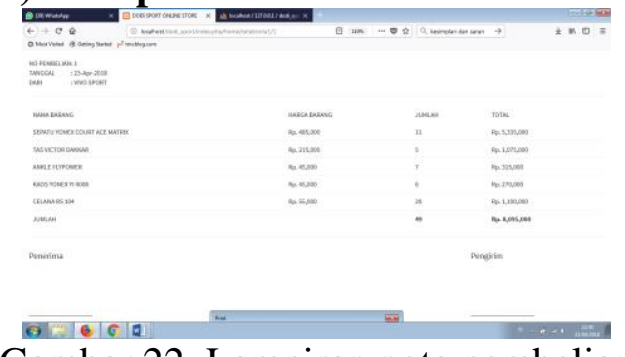

Gambar 22. Lampiran nota pembelian

\section{KESIMPULAN}

Berdasarkan hasil analisa dan perancangan pada Implementasi Supply Chain Management (SCM) pada toko alat-alat olah raga berbasis web. Study kasus Dodi Sport, maka diperoleh kesimpulan sebagai berikut :

1. Sistem ini dibuat untuk memudahkan dalam pengelolaan data barang.

2. sistem ini di buat untuk mengecek stock barang agar tidak terjadi kekurangan atau kelebihan barang.

3. Pada Sistem ini dapat melaporkan kepada bagian Owner sehingga untuk pengecekan barang yang masih tersedia dan juga pengeluaran barang dapat di lihat dari laporan tersebut tanpa harus mengecek langsung ke gudang.

4. Dengan adanya fasilitas ini antara pihak suplier dengan bagian Gudang dapat berkomunikasi dan saling memberikan informasi tentang stock barang dengan mudah, sehingga dapat meningkatkan proses bisnis yang maksimal.

\section{SARAN}

Setelah penulis mengadakan penelitian, maka ada beberapa saran yang ingin penulis kemukakan agar aplikasi berjalan maksimal, antara lain:

1. Untuk mengoperasikan program aplikasi ini, diperlukan adanya sosialisasi terlebih dahulu terhadap Admin Gudang maupun dengan pihak supplier.

2. Pengisian data barang dan harga barang harus di isi oleh bagian Supplier agar bagian Gudang mengetahui harga yang ditawarkan oleh distributor atau supplier.

3. Jika ada transaksi pencatatan data penjualan barang penulis, menyarankan untuk membuat aplikasi khusus penjualan karena dalam aplikasi ini tidak begitu detail menangani masalah 
penjualan maupun promosi barang.

\section{DAFTAR PUSTAKA}

Usman, Nurdin. (2002). Konteks Implementasi Berbasis Kurikulum. Jakarta:PT. Raja Grafindo Persada.

Setiawan, Guntur. (2004). Implementasi Dalam Birokrasi

Pembangunan.

Bandung:Remaja Rosdakarya Offset.

Harsono, Hanifah. (2002). Implementasi Kebijakan dan Politik. Bandung:PT. Mutiara Sumber Widya.

Agustino. 2006. Implementasi Kebijakan Publik Model Van Meter Van Horn:The Policy.

Abdul Kadir, 2003, Pengenalan Sistem Informasi, Andi, Yogyakarta.

Poerwadarminta. W.J.S. 2003. Kamus Umum Bahasa Indonesia. Jakarta : Balai Pustaka.

Indrajit, Richardus Eko dan Djokopranoto. (2003).

Konsep Manajemen Supply Chain : Strategi Mengelola Manajemen Rantai Pasokan Bagi Perusahaan Modern di Indonesia, PT Gramedia Widiasarana Indonesia, Jakarta.

Perkins \& Waligum, "Supply Chain Management Definition and FAQs". Diakses tanggal 25 Oktober 2017 dari https://www.cio.com/article/2 439493/supply-chainmanagement/supply-chainmanagement-supply-chainmanagement-definition-andsolutions.html

Schroeder, Roger G., 2000, Operations Management: Contemporary Concepts and Cases,
p-ISSN : 1858-3911, e-ISSN : 2614-5405

https://journal.uniku.ac.id/index.php/ilkom
International Edition, Mc Graw-Hill Companies, Inc., Boston.

A.S Rosa dan Salahuddin M, 2011. Modul Pembelajaran Rekayasa Perangkat Lunak (Terstruktur dan Berorientasi Objek), Modula, Bandung.

Chopra, Sunil dan Peter Meindl. 2010. Supply chain management: Strategy, planning, and operations. New Jersey: Prentice Hall.

Chaffey, D. (2002). E-business and Ecommerce management. Strategy, Implementation and Practise. USA: Financial Time.

Kalakota, Ravi \& Maria Robinson. 2001. E-Business 2.0 : Roadmap for Success. Addison Wesley, Longman Inc., USA.

Sianipar, R.H. 2015. HTML5 \& CSS3. Bandung: Informatika.

Fathansyah, 2012, Basis Data, Bandung: Informatika.

Scott W Ambler, The Elements of UML 2.0 Style. Cambridge,UK, 2005.

Rosa AS dan M.Shalahuddin. 2015. Rekayasa Perangkat Lunak Terstruktur Dan Berorientasi Objek Bandung INFORMATIKA. 